\title{
A Computational Tool for Supporting Problem-Based Learning in the Teaching-Learning Process
}

\author{
Francisco Milton Mendes Neto',2, Elys Gardênia de Freitas Lopes ${ }^{1,2}$, \\ Lucianna Marylin Batista de Almeida1,2, Danilo Gomes Carlos ${ }^{3}$, Fernando Henrique Alves ${ }^{3}$ \\ ${ }^{1}$ Centro de Ciências Exatas e Naturais, Mossoró, Brazil \\ ${ }^{2}$ Pró-Reitoria de Graduação, Mossoró, Brazil \\ ${ }^{3}$ Universidade Federal Rural do Semi-Árido, Mossoró, Brazil \\ Email:miltonmendes@ufersa.edu.br,elysfreitas@ufersa.edu.br,lucianna@ufersa.edu.br, \\ danilogomescarlos@hotmail.com,fernando.everywhere@gmail.com
}

How to cite this paper: Neto, F. M. M., de Freitas Lopes, E. G., de Almeida, L. M. B., Carlos, D. G., \& Alves, F. H. (2018). A Computational Tool for Supporting Problem-Based Learning in the Teaching-Learning Process. Creative Education, 9, 1654-1666.

https://doi.org/10.4236/ce.2018.911120

Received: June 30, 2018

Accepted: August 28, 2018

Published: August 31, 2018

Copyright $\odot 2018$ by authors and Scientific Research Publishing Inc. This work is licensed under the Creative Commons Attribution International License (CC BY 4.0).

http://creativecommons.org/licenses/by/4.0/

\section{(c) (i) Open Access}

\begin{abstract}
The Problem-Based Learning (PBL) is an active teaching methodology developed through self-directed study and group work, with the objective of problem solving. However, using this methodology, some challenges appear in its implementation, for example, the difficulty of monitoring conversations unrelated to the context of the proposed problem, distancing itself from the center of the discussion and committing the learning objectives. Another factor to be considered is the formation of groups, since the methodology does not establish criteria for how to select the teams so that they are distributed in a heterogeneous way. The supervision of accomplishment of the PBL implementation cycle also requires from the facilitator frequent monitoring for the effectiveness of the methodology, representing a task that is difficult to verify, when it refers to the application of the individual or autonomous study. In this sense, this work presents a computational tool to support the PBL, which aims to contemplate the above-mentioned difficulties inherent to the implementation of this methodology and to assist in the teaching-learning process.
\end{abstract}

\section{Keywords}

Problem-Based Learning, Problem Tool, Multi-Agent System, Modular Object-Oriented Dynamic Learning Environment, Medicine

\section{Introduction}

Currently, reflecting education without emphasizing the use of technologies in 
the process of knowledge formation becomes a decontextualized task. Therefore, the appearance of technological resources and new teaching methodologies in the learning space alters the role of the student and the teacher and, consequently, the ways of teaching and learning.

The technologies can be considered tools that allow the dynamization of the teaching-learning process, through diverse ways of interaction between student and teacher in the resolution of an educational task, that transcend the barriers of physical space previously delimited and that contributed to the learning occurs in a collaborative way, in which the student shares with others the knowledge, doubts and impressions generated in the teaching space. In this approach, Distance Education (DE) emerges as a modality and as an instructive tool supported by the use of technological resources and pedagogical procedures, allowing greater flexibility of time and space of study, adaptable to the user profile, in addition to promoting the expansion of pedagogical practices directed to the construction of collaborative learning (Cleveland-Innes, 2010).

According to Dimitracopoulou (2005), the computational support for collaborative learning is called Computer-Supported Collaborative Learning (CSCL). In this approach, the systems that implement collaborative learning must insert cooperation and communication resources, enabling the learning process to present a satisfactory level of quality. In the sequence, it also emphasizes the need of these systems enable to the facilitators' mechanisms of formation and monitoring of groups.

The PBL is an active teaching methodology that alters the perspective of how the teaching-learning process occurs, bringing to the student and the teacher, respectively, the protagonist figure of the learning process and of facilitator. In this way, it is seen as an innovative methodology, allowing the knowledge to be acquired in a self-directed way. The dynamics of this methodology employs the use of problems as a mechanism to stimulate learning and how to develop skills, in which students learn while interacting in solving a proposed problem (Hmelo-Silver, 2004). The presentation of the problem is directed to small groups, which interact in collaboration, seeking to identify the contents to be assimilated, thus contemplating the learning objectives defined by the teams.

Based on the application of the PBL, the proposed problems can be formulated taking as reference the use of various sources, for example, using tools of Information and Communication Technology (ICT), being able to use Virtual Learning Environments (VLE) in the content approach, which allows the interaction and exchange of information (Borges, Chachá, Quintana, Freitas, \& Rodrigues, 2014). Thus, the execution of the methodology proposed in this work was applied together with a computer tool named Problem, which was developed in VLE Moodle (Modular Object-Oriented Dynamic Learning Environment), specifically created to support the cycle of application of Problem-Based Learning, allowing it to be applied in the blended or online format. The implementation of this tool aims to assist the facilitator and the students in the im- 
plementation of the seven steps of the PBL cycle, contributing to the teaching-learning process, as well as the possibility of minimizing difficulties related to student dispersion, the formation of support groups and the accompaniment of the individual or autonomous study referring to the stage of resolution of the proposed problem. The use of the tool was applied through the case study procedure and counted on a sample of 25 students from the fourth period of the medical school of the Universidade Federal Rural do Semi-Árido (UFERSA).

The structure of this work is organized as follows: Section 2 presents the main concepts related to PBL, Section 3 presents the computational tool for supporting PBL, in Section 4 is presented the case study and at Section 5 are presents the final considerations and future work.

\section{Problem-Based Learning}

The arising of this methodology of teaching occurred in 1960, proposed by a team of professors of the University of McMaster, in Canada. The main members of this group were Howard Barrows, Jim Anderson and John Evans, the first being the main articulator (Savin-Baden \& Major, 2004). It was initially developed and applied in the medical school and, subsequently, extended to other areas of knowledge. In Brazil, PBL was initially introduced at the Faculdadede Medicina de Marília (FAMEMA), in 1997. Later, it was implanted at the Universidade Estadual de Londrina (UEL), in 1998. Currently, this methodology has been extended to other educational institutions located in Brazil and abroad. With this, it can be affirmed that this methodology has been used as a support for learning in different countries.

The initial procedure for the application of PBL consists in the use of problem situations in a contextualized way, with the aim of conducting and stimulating the learning (Berbel, 1998). For Savin-Baden and Major (Savin-Baden \& Major, 2004), problems must be characterized by different levels of complexity, starting from situations of minor to greater degree of difficulty.

The systematization of the PBL requires the observance of seven sequential execution steps proposed by the University of Maastricht. Thus, considering the Maastricht referential, a working group should solve a problem situation, taking as reference the following steps: 1) Reading of the problem situation and clarification of unknown terms, 2) Identification of the proposed problem by the statement, 3) Discussion of the problem and formulation of hypotheses to solve it, 4) Summary of hypotheses, 5) Formulation of learning objectives, 6) Autonomous study of the subjects raised in the previous step, and 7) Return to the tutorial group to discuss the problem again with the new knowledge acquired in the autonomous study phase (Maastricht University, 2018).

In order to the accomplishment of the seven steps mentioned above, it is necessary to perform two tutorial sessions (opening and closing), developed through the formation of work groups, consisting of a maximum of 10 participants in each 
team. In the opening phase of the tutorial session the sequence of steps 1) to 5) is applied. Between the opening and closing phases, it must complete the sixth step of the cycle, to then proceed to the closing phase, which corresponds to the last step of the PBL cycle (Barrows \& Tamblym, 1980).

\section{Computational Tool for Supporting PBL}

The computer tool named Problem was developed in VLE Moodle. The justification for using this platform was due to the following factors: because it is an educational environment that has been significantly used by educators and because it is open source software, which allows the creation of computational tools according to the characteristics defined by developer (Moodle, 2018).

The purpose of creating this tool is to assist the facilitator and the students in the application of the PBL cycle, making it possible to minimize the difficulties of implementing this methodology, properly described in the introduction of this work.

The Problem tool has two interfaces, defined as follows: Use Scenario of the Facilitator and Use Scenario of the Student. The use scenario for the facilitator is composed of two tabs, presented as follows: Problem and List of Group. As for the use scenario assigned to the student, this is formed by four tabs: Problem, Group, Sessions and My Profile. In addition to the functionalities, the Problem tool also has chat and forum resources, which were used as collaborative tools, in order to allow interaction between the facilitator and the students during the problem-solving phase. Figure 1 and Figure 2 show, respectively, the use scenarios of the facilitator and student, which are presented after completing the user authentication steps and choosing the course and the problem to be solved.

To minimize the difficulties of PBL implementation related to student dispersion, the formation of support groups and the monitoring of the individual or autonomous study related to the problem solving stage, the Problem tool has a Multiagent System (MAS) that aims to assist in this process and, consequently, to surpass such challenges.

According to Henderson-Sellers \& Giorgini (2005), MAS can be defined as a system formed by two or more agents that compete or cooperate with each other for the purpose of performing tasks or achieving one or more objectives. Thus, in order to perform tasks related to the application of PBL cycle, some agents have been inserted in the Problem tool. It is important to emphasize that only the agents that specifically work in minimizing the difficulties of PBL implementation were mentioned in this paper. In this approach, the following agents stand out:

- Group Management Agent (GMAg), whose main function is recommending the formation of groups that have an approximate or desired profile to solve specific problems, that acts after the facilitator to define the profiles of the groups and the learning goals; 
Dados do problema

Doença de Chagas pega "carona" na lesão celular.

Como o Trypanosoma cruzi causa a lesão celular, aproveita-se do mecanismo de reparo para invadir a célula hospedeira e causa a doença de Chagas?

O mecanismo de reparo celular influencia a infecção pelo $T$ cruzi, o tropismo, causando a doença de Chagas.

Áreas de conhecimento: Biologia e Saúde.

Metas de aprendizagem

Descrição

Compreender os mecanismos de lesão e reparo celular

Conhecer as características gerais dos protozoários, com ênfase no T. cruzi (ciclo de vida, resposta imune)

H Adicionar meta de aprendizagem

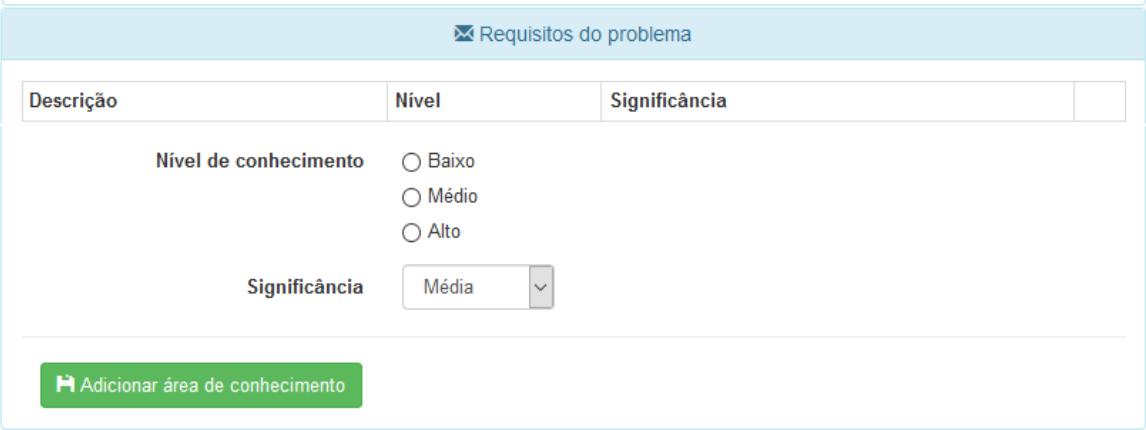

Figure 1. Use scenario of the facilitator.

A Problema Grupo $\equiv$ Sessões 2 Meu perfil

Doença de Chagas pega "carona" na lesão celular.

Como o Trypanosoma cruzi causa a lesão celular, aproveita-se do mecanismo de reparo para invadir a célula hospedeira e causa a doença de Chagas?

O mecanismo de reparo celular influencia a infecção pelo $T$ cruzi, o tropismo, causando a doença de Chagas

Áreas de conhecimento: Biologia e Saúde.

\section{Termos desconhecidos}

Cite no campo abaixo, os termos contidos na descrição do problema que você desconhece separados por vírgula:

Tropismo.

H Salvar termos desconhecidos

Figure 2. Use scenario of the student. 
- Group Monitoring Agent (GMoAg), which is responsible for monitoring the process of accomplishment and finalization of the activities carried out by the members of the group, supervising the cycle of execution of the PBL methodology;

- Session Monitoring Agent (SMAg), which verifies the condition of the opening and closing sessions;

- Problems Detector Agent (PDAg), which performs the functions of detection of collaboration problems of the teams during the accomplishment of the sessions and in the stage of the problem finalization, acting together with GMoAg and SMAg, which are triggered when are observed students' passivity behaviors, conversations not related to the context of the problem, not sending the reports and evaluations of the sessions, when the problem solving session was not finalized, the final report and problem solving were not sent and when not performed student and peer evaluations. Detecting the non-accomplishment of these tasks, the PDAg notifies the facilitator and the components of the groups, in order to contemplate them and follow the PBL steps, since, the main purpose of the MAS in this work is to help in application of the cycle of this methodology in Moodle, contributing to the teaching-learning process.

For the monitoring of the individual or autonomous study, collaborative chat and forum tools were used to help the dialogues and functionalities between the working groups during the problem solving phase, contributing to the practical application of the approached contents.

\section{Case Study}

The Problem computational tool was used as an instrument of data collect, through the case study procedure. The research was developed at the Universidade Federal Rural do Semi-Árido, located in the city of Mossoró, in the state of Rio Grande do Norte. The application of the study obtained a sample of $25 \mathrm{stu}-$ dents of the fourth period of the medical school of the Institution.

In order to perform the case study, it was necessary to obey the sequence of the following application phases: 1) submission and approval of the project by the Ethics Committee in Research (ECR) (technical opinion $\left.\mathrm{N}^{\circ} 2,331,997\right) ; 2$ ) consent of the proposing institution; 3 ) consent of the sample participating in the research, by means of a signature expressed in the Statement of Free and Clarified Consent ${ }^{1}$ (SFCC); 4) definition of the schedule and stages of the activities execution; 5) presentation of the interfaces and the way of operation of the Problem tool; 6) monitoring the activities and stages applied in the study; 7) validation; and 8) collect and analysis of data.

Referring to the schedule and the description of the activities proposed to be

${ }^{1}$ A document that highlights the rights, permissions, responsibilities, requirements, objectives, and risks of those involved in the research, with the aim of ensuring the confidentiality of information, anonymity of participants and the protection of researchers about the use and dissemination of results, respected the accomplishment of the requirements. 
accomplished in the tool, these occurred as follows: the facilitators made available to the participants two problem situations for resolution, and the application of the first occurred in the period from March 12 to 19 of 2018 and the second was performed in the period from March 26 to April 2 of that year. During this stage, frequent systematic observations of this process were made, with the purpose of monitoring the ways of problem solving; the access to reports available in the tool; the interaction, performance and collaboration of the participants; evaluation feedback and supervision of the accomplishment of the PBL cycle in problems solving.

The proposed problem situations were introduced respecting the order and accomplishment of the seven steps considered essential for the application of the PBL and for obtaining the results. The first step was carried out by the facilitators involved in the research, by registering and linking the groups to the problems in the tool. The second step was done in-person in the tutoring rooms, following the formation of the teams defined by the facilitators, counting on the distribution of 4 (four) tutorial groups (TG), as described: TG1, composed of nine members; TG2, with eight and TG3 and TG4, with nine members in each group. At that moment, were performed the first five steps of the PBL cycle, already mentioned in section 2 , which correspond to the opening phase of the sessions.

Subsequently, was applied the sixth PBL implementation step, which consists of the individual study. The accomplishment of this moment occurred in a blended way, with the aid of the Problem computational tool. To this, the facilitators created forums for discussion in-group, based on the learning objectives defined by each team, aiming to have a space for sharing information and materials, of inclusion and achievement of doubts and allowing facilitators follow the group's discussions. With the use of this resource, it was possible to diagnose possible collaborative difficulties presented by the students during their individual study, allowing the facilitator, respected the right of the student autonomy, to intervene when necessary in order to achieve the learning objectives and solving the problem.

In the closing session of the problem, the last step of the methodology was applied in in-person format. Thus, the groups returned to the tutoring rooms with the purpose of debating again the proposed problem situation in view of the new knowledge acquired during the autonomous study phase. After the discussions were made and the learning objectives were answered, the problem was closed, respecting the considerations of the group and the facilitators. After the problem was closed, the facilitators performed the evaluation of the students, based on the defined learning goals and in the observation of the level of participation of each member of the team (criterion used: score from 0 to 10) and the students performed the self-assessment, peer evaluation and submission of the final report and of the problem solving, procedures performed in a blended way, through the Problem tool. 
After the application phase of the tool, the validation procedure was carried out. For this, two evaluation questionnaires were used as data collect instruments. The first one was responsible for validating the methodology and the second the computational tool, both composed of seven questions each, combining two question models, with closed questions and in the open dependent structure. For the technique of data analysis, it was chosen descriptive statistics, which allows combining quantitative and qualitative data.

The data presented in this work correspond to a synthesis of the results obtained regarding the tool evaluation questionnaire, aiming to emphasize the application process of the Problem computational tool in the PBL proposal and its effectiveness in the teaching-learning process. In this approach, we will specifically refer to the questions that refer to the stages of use of the tool during the problem solving phase, group performance, learning process and student assessment of (ICT) use in education. Considering the above, we present the following results, based on a sample of 25 participants.

From Figure 3, it can be inferred that the execution stages of the activities proposed in the computational tool were applied in an appropriate way, respecting the application of the PBL cycle, which demonstrates the effectiveness of the combination of the tool and the proposed methodology. Thus, only $32 \%$ of the sample presented some type of difficulty. Based on the responses indicated, the following difficulties and their respective percentages were highlighted: 1) difficulty in accessing the tool (12.5\%); 2) difficulty with the interface of the tool (62.5\%); and 3) difficulty with the use of the forum (25\%).

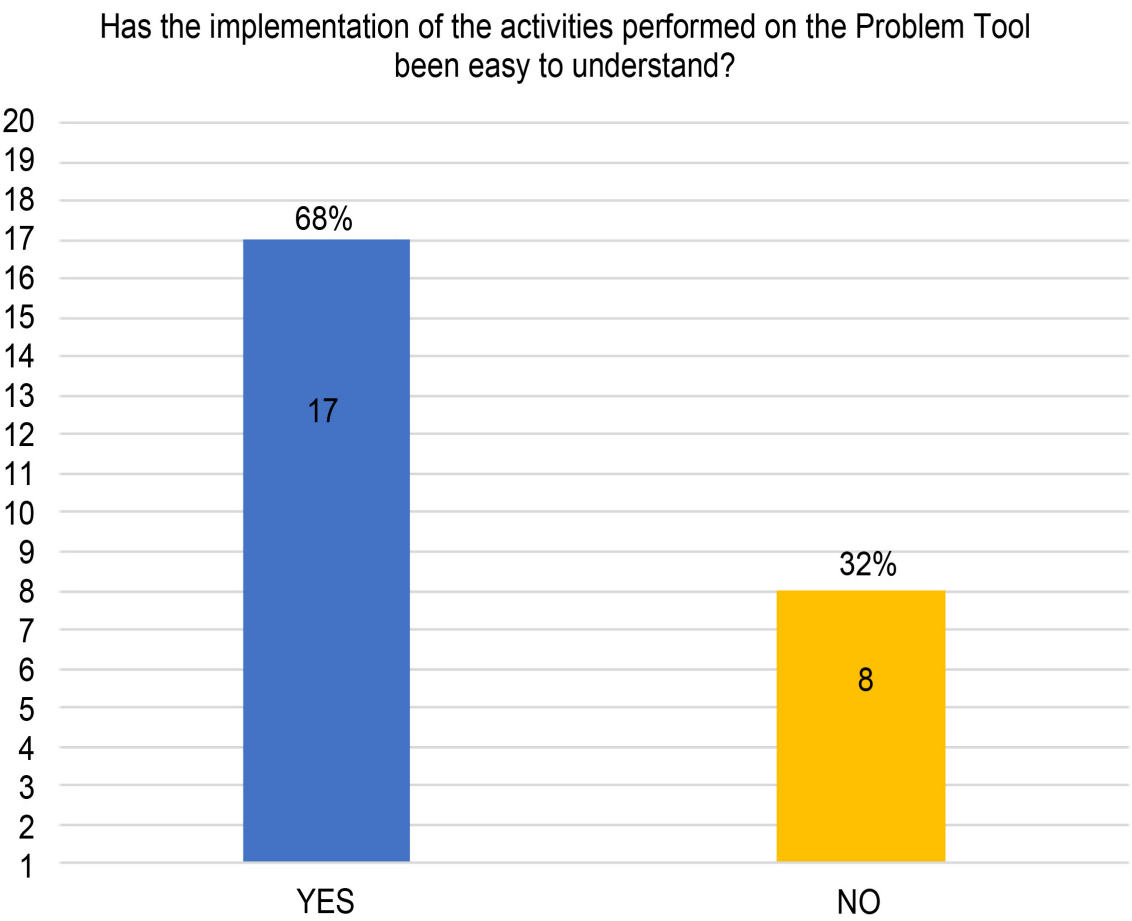

Figure 3. Stages of activities application in the problem tool. 
Based on the data presented in Figure 4, it can be concluded that there was a higher incidence of evaluations directed at favorable considerations regarding the performance of the group, which shows the functionality of the tool and the practical exercise that this allows for the application of the PBL in the blended learning format. The fact that most participants consider the performance of the group regular demonstrates an understanding that they were submitted to a teaching format and to the use of a technology that requires a period of adaptation to obtain a better performance. Regarding the evaluations considered not satisfactory, the participants presented the following justifications and their respective percentages: 1 ) due to the non-participation of all members of the group during the activities in a satisfactory way (70\%), reason that presented as main justification the low availability of students' time due to the requirements of the workload presented by the medical school; 2) adaptation to the tool (10\%); and 3 ) by the fact of not perception of differences in the application of the PBL in the blended format compared to the in-person format already used by the participants (20\%).

Regarding the data presented in Figure 5, it can be stated that the use of the tool propitiated the learning process during its period of use, allowing the application of the PBL cycle to occur dynamically and more participatory. The collaborative resources of chat and forum assisted in the execution of the sixth step of the methodology, which consists of the student's individual or autonomous study, favoring the sharing of students' information and doubts. This also enabled the facilitator to provide evaluation feedback on student performance, if observed deviations in the resolution of the learning objectives to be reached, besides allowing the contents registered in the tool to be stored and accessible in

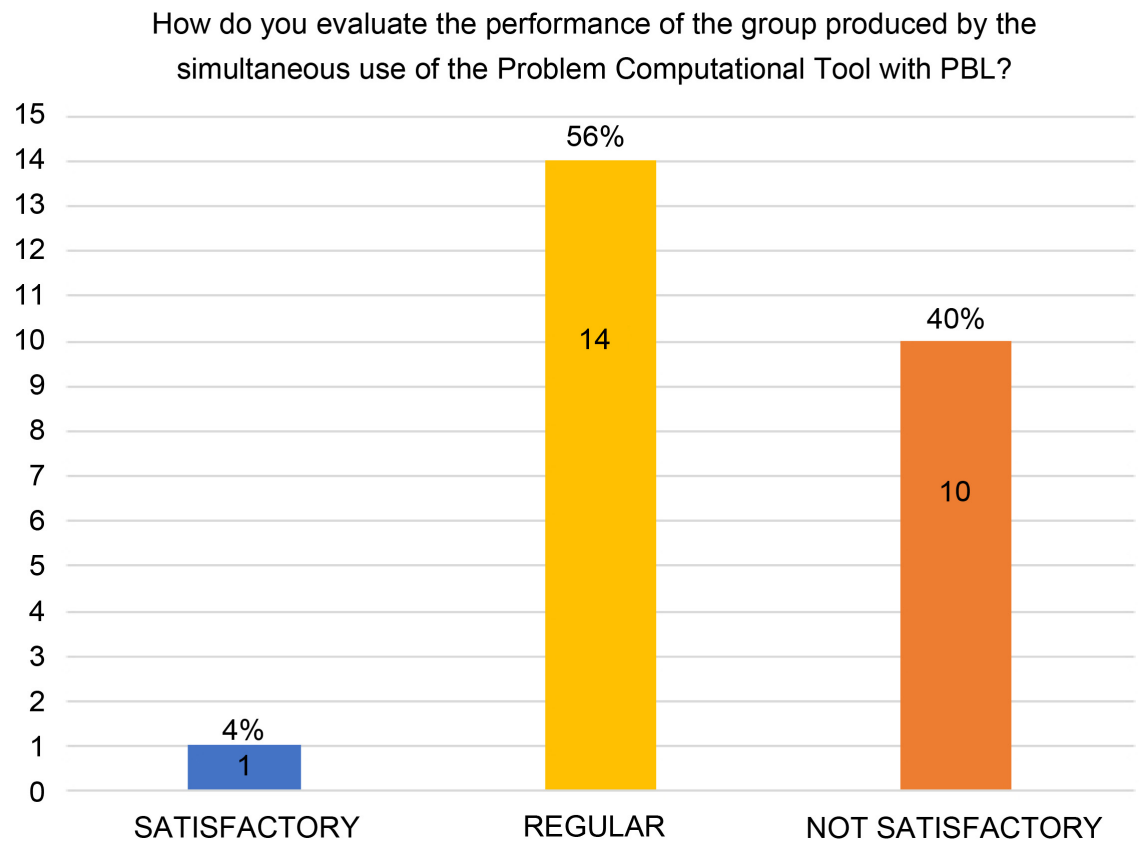

Figure 4. Performance of the tutorial group in the problem tool. 
Did the implementation of activities in a blended way contribute to the development of activities?

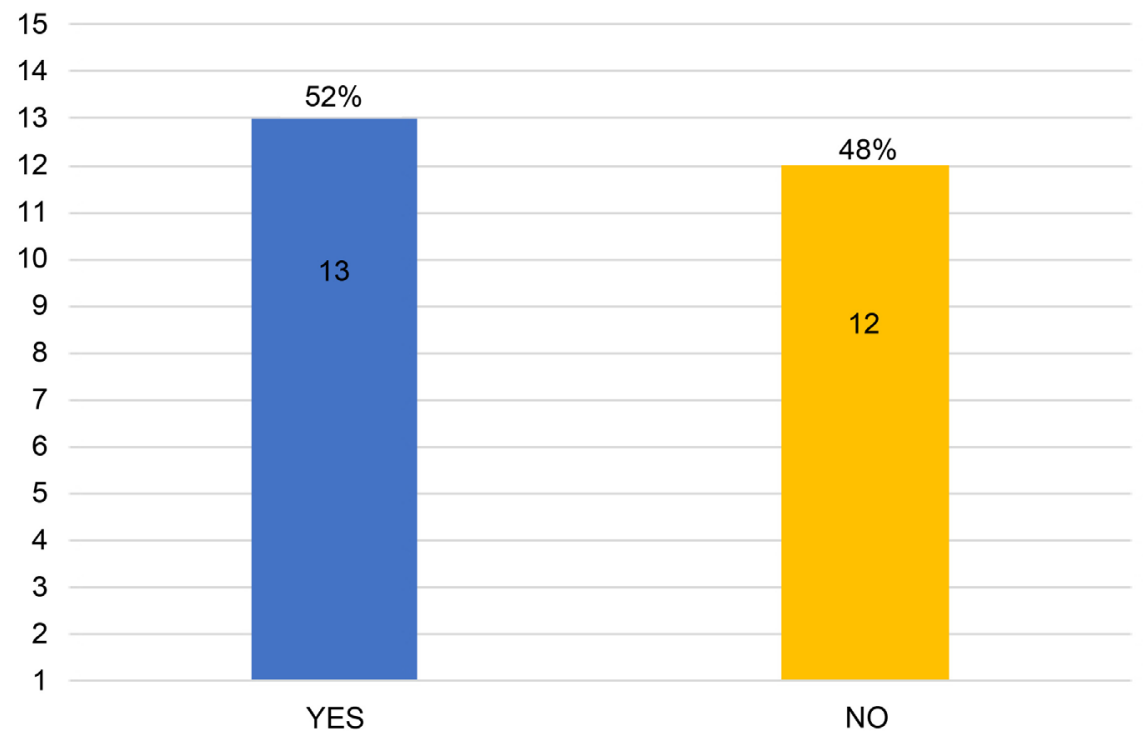

Figure 5. Evaluation of learning development.

a practical way, whenever demanded. Regarding the evaluations that took into account that the activities applied in the tool, in the blended format, did not favor learning, the following reasons and their respective percentages were recorded: 1) due to the non-use of the resources and the functionality of the tools in satisfactory way, justified by lack of time $(25 \%) ; 2$ ) due to their adaptation to the tool $(41.6 \%)$, since they stated that they were adapted with the use of other technological tools to support the application of the methodology; 3) because they preferred the PBL application in person (16.7\%) and $16.7 \%$ did not justify it.

From the data obtained in Figure 6, it is possible to affirm that ICT are considered essential instruments in the educational scope. In this way, they can be used as pedagogical support for the complementation of learning, since they constitute a legally recognized resource in Brazil, after the promulgation of Law number 9394/96, which deals with the Guidelines and Bases of Education (GBE). In this sense, the Problem tool represents a fundamental technological resource to aid the teaching-learning process in the PBL proposal, since it allows the expansion of teaching formats through the DE modality, in addition to facilitating the application of more participative classes, collaborative resources, which instigates the student's performance in the construction of knowledge.

It is important to note that, during the use of the Problem tool, conversations not related to the context of the problem were not diagnosed. One of the reasons that contributed to the non-occurrence of this factor was due to the strategy of the facilitators in creating specific forums for each learning objective defined by the groups during the realization of the tutorial sessions, these were recorded as learning goals. Thus, the discussions were restricted to the context of the problems 
Do you consider relevant the use of ICT in education?

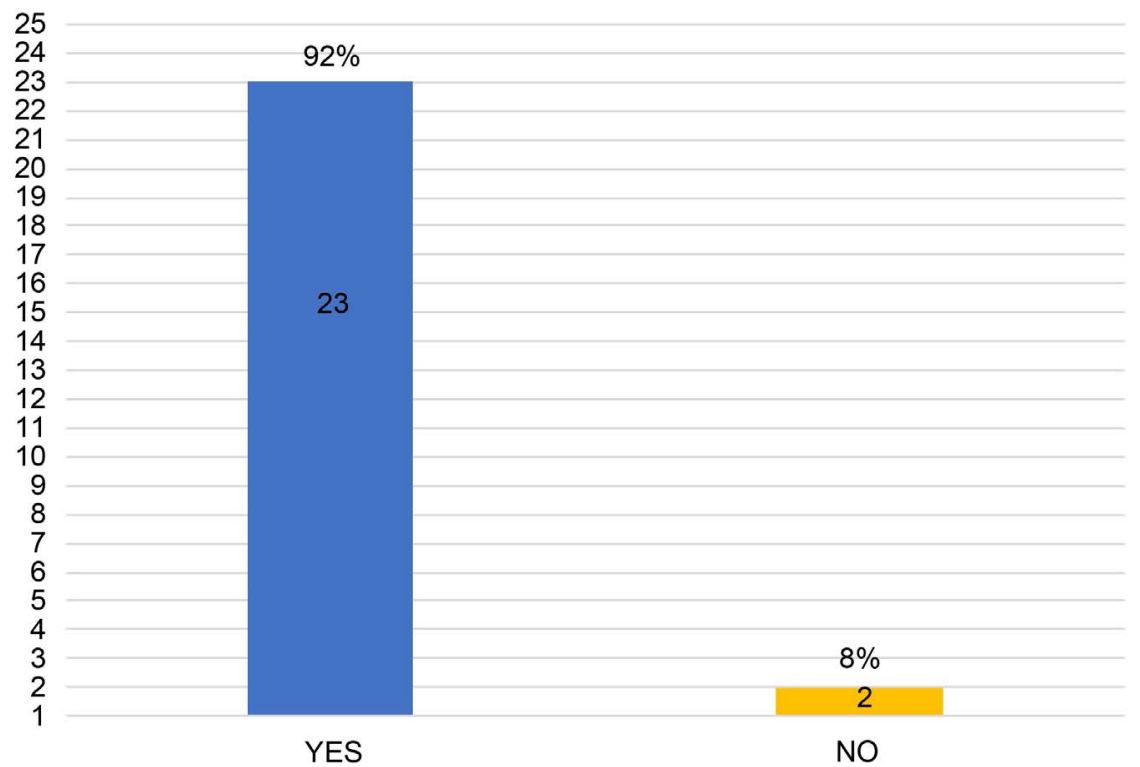

Figure 6. Assessment of ICT in education.

to be solved and, at the same time, allowed the facilitators to monitor the individual and collective study of the students, to follow the students' performance, their strategies of solution of the problem situations; the forms of participation and, consequently, to achieve the learning objectives and the resolutions of the problems. As a result of the contributions arising from this strategy, it was possible to carry out the final evaluation of the students and the group in a more precise way, based on observations of the individual and collective performance of the teams. Therefore, each learning objective was a goal. Thus, the students were evaluated according to the individual performance achieved in each learning goal, and the group according to the general performance presented during all the steps of application of the methodology.

Learning goals compose a set of characteristics that are directed to the individual profiles of the students after the facilitators make the final evaluation, and are used by the MAS when the need to create the support groups is required. In this way, the Problem tool enables facilitators to have two formats for group formation: manually, individually linking each participant to the problem, or using the MAS, which creates the groups automatically, based on the problem's requirements and the learning goals.

As discussed in this work, it can be stated that the above-mentioned tool makes it possible for teaching to go beyond the space-time linearity of the classroom, combining different ways, forms and proportions of knowledge formation, as well as allowed to minimize challenges implementation of the PBL, regarding the formation of groups, the monitoring of conversations not related to the context of the problem and the monitoring of the individual or autonomous study of the students, assisting in the accomplishment of educational activities 
and in the application of the proposed methodology, aiming to contribute to the teaching-learning process.

\section{Final Considerations and Future Work}

Using the PBL as a teaching methodology extends the ways of performance of the student and facilitator in the space of learning, as well as promotes the development of skills and competences; of autonomy; of the interaction, collaboration and participation forms, and of the argumentative and critical capacity, contributing to the accomplishment of more dynamic classes, with the purpose of instigating curiosity and the learning process.

The PBL application emphasizes group work and collaboration to solve a problem. During this process, there are some difficulties inherent to the methodology, such as the dispersion of students in collaborative learning environments, the creation of support groups and the monitoring of individual and collective study, which influence and compromise the learning, if no restorative measures are adopted.

In view of the above, this paper presented a computational tool to support the $\mathrm{PBL}$, which integrates software agents with the purpose of minimizing the difficulties of implementing this methodology, previously described and facilitating the learning process, enabling the intermediation among those involved during the individual and/or collective interaction occurring in the resolution phase of a proposed problem, even if the actors included in this process are separated in different physical environments. However, it is important to highlight that the use of technologies in the educational space requires the planning and the adoption of pedagogical practices that enable the participatory performance of all those involved and who aim to follow the learning generated in this process. In this sense, we present as contribution of this work the development of a computational tool to attend the main application requirements of the PBL, in order to help in obtaining pedagogical data related to the teaching-learning process, aiming to verify the effectiveness of the combination of the tool with the PBL in learning.

As a proposal for future work, we intend to implement the problem tool, creating other functionalities and improving some existing ones, in order to help students and facilitators in the application of the PBL and to contribute to the learning process. One of the suggested functionalities for improvement is to allow the tool to generate, after peer evaluation, a report with the average performance of all the groups linked to the problem. This report should be available both in the student and the facilitator use scenario, allowing access only to the members and facilitators of their respective tutorial groups, thus facilitating the monitoring of individual and collective performance, evaluation and self-assessment process. Another proposal is to create a specific space for the sending materials of the student individual production, without being stored in the problem solving form, because at the moment they are accessible to all members of the group. 
Thus, the creation of this resource will allow the individual material to be available only to the student (author of the content) and for the group facilitator and may serve as an additional instrument in the student's assessment. Finally, we suggest, after the closing of the problem, the change the evaluation criterion of the student, currently represented by a score scale that includes values from zero to ten, for the creation of concepts of student performance, considering the criteria satisfactory, regular and need to improve.

\section{Conflicts of Interest}

The authors declare no conflicts of interest regarding the publication of this paper.

\section{References}

Barrows, H. S., \& Tamblym, R. M. (1980). Problem-Based Learning: An Approach to Medical Education (p. 224). New York: Springer Publishing Company.

Berbel, N. A. N. (1998). Problematization and Problem-Based Learning: Different Words or Different Ways? Interface Communication, Health, Education, 2, 139-154.

Borges, M. C., Chachá, S. G. F., Quintana, S. M., Freitas, L. C. C., \& Rodrigues, M. L. V. (2014). Aprendizado Baseado em Problemas. Medicina, 47, 301-307. https://doi.org/10.11606/issn.2176-7262.v47i3p301-307

Cleveland-Innes, M. F. (2010). Teaching and Learning in Distance Education: Enter a New Era. In M. F. Cleveland-Innes, \& D. R. Garrison (Eds.), An introduction to Distance Education: Understanding Teaching and Learning in a New Era (pp. 1-12). New York: Routledge.

Dimitracopoulou, A. (2005). Designing Collaborative Learning Systems: Current Trends and Future Research Agenda. Proceedings of the 2005 Conference on Computer Support for Collaborative Learning: Learning 2005: The Next 10 Years! Taipei, 30 May-4 June 2005, 115-124. https://doi.org/10.3115/1149293.1149309

Henderson-Sellers, B., \& Giorgini, P. (2005). Agent-Oriented Methodologies (pp. 317-340). Guernsey, Reino Unido: IGI Global. https://doi.org/10.4018/978-1-59140-581-8

Hmelo-Silver, C. E. (2004). Problem-Based Learning: What and How Do Students Learn? Educational Psychology Review, 16, 235-266. https://doi.org/10.1023/B:EDPR.0000034022.16470.f3

Maastricht University (2018). Problem-Based Learning. https://www.maastrichtuniversity.nl/education/why-um/problem-based-learning

Moodle (2018). About Moodle. http://moodle.org/about/

Savin-Baden, M., \& Major, C. H. (2004). Foundations of Problem-Based Learning (p. 198). New York: Society for Research into Higher Education \& Open University Press. 